
Revista USP / Superintendência de Comunicação Social da Universidade de São Paulo. - N. 1 (mar./maio 1989) - São Paulo, SP: Universidade de São Paulo, Superintendência de Comunicação Social, 1989-

Trimestral.

Continuação de: Revista da Universidade de São Paulo

Descrição baseada em: N. 93 (2012)

ISSN 0103-9989

1. Ensaio acadêmico. I. Universidade de São Paulo.

Superintendência de Comunicação Social 


\section{dossiê universidade em movimento}

5 EDITORIAL

8 APRESENTAÇÃO Jacques Marcovitch

9 ALGUNS DESAFIOS PARA O FINANCIAMENTO DAS UNIVERSIDADES PÚBLICAS ESTADUAIS DO ESTADO DE SÃO PAULO Carlos Antonio Luque

190 DESEQUILÍBRIO FINANCEIRO DA UNIVERSIDADE DE SÃO PAULO: ORIGENS E MEDIDAS DE AJUSTE Vahan Agopyan e Rudinei Toneto Jr.

33 AUTONOMIA UNIVERSITÁRIA E LEI DE RESPONSABILIDADE FISCAL: RELAÇÕES E IMPLICAÇÕES Nina Ranieri

43 UNIVERSIDADE EM MOVIMENTO Jacques Marcovitch

51 EM BUSCA DA EXCELÊNCIA José Goldemberg

65 AVALIAÇÃO: RESULTADOS, TENDÊNCIAS E DESAFIOS Luiz Nunes de Oliveira

75 USP: 0 ÊXITOE A CRISE Sergio Adorno

\section{arte}

89 ANTONIO HENRIQUE AMARAL: A CARA DO BRASIL NA ARTE BRASILEIRA Simone Rocha de Abreu

\section{textos}

107 JACÓ GUINSBURG E A EDITORA PERSPECTIVA Roberto Romano

113 PINHEIRO CHAgAS E OS NEFELIBATAS Alvaro Santos Simões Junior

\section{livros}

125 ENCONTRO DE CULTURAS Alberto Alves da Fonseca

131 CLÁSSICOS ILUSTRADOS Lucia Wataghin 
A revistaunsp é uma publicação trimestral da Superintendência de Comunicação Social (SCS) da USP. Os artigos encomendados pela revista têm prioridade na publicação. Artigos enviados espontaneamente poderão ser publicados caso sejam aprovados pelo Conselho Editorial. As opiniões expressas nos artigos assinados são de responsabilidade exclusiva de seus autores.

\section{UNIVERSIDADE DE SÃO PAULO}

Reitor MARCO ANTONIO ZAGO

Vice-reitor VAHAN AGOPYAN

SUPERINTENDÊNCIA DE COMUNICAÇÃO SOCIAL

Superintendente MARCELLO CHAMI ROLLEMBERG

revistaungp

Editor chefe FRANCISCO COSTA

Editor executivo JURANDIR RENOVATO

Editora de arte LEONOR TESHIMA SHIROMA

Webmaster SANDRA A. MARQUES GUIRAL

Revisora CLEUSA CONTE

Secretária MARIA CATARINA LIMA DUARTE

Conselho Editorial

ANA MARIA SETUBAL PIRES-VANIN

ANTONIO BELINELO

CHESTER LUIZ GALVÃO CESAR

LISBETH RUTH REBOLLO GONÇALVES

MARCELLO CHAMI ROLLEMBERG

OSWALDO UBRÍACO LOPES

PAULO DOMINGOS CORDARO

PAULO NATHANAEL PEREIRA DE SOUZA

CTP, Impressão e Acabamento

IMPRENSA OFICIAL DO ESTADO DE SÃO PAULO

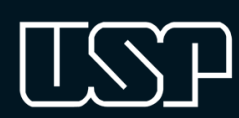

Rua da Praça do Relógio, 109 - Bloco L - $4^{0}$ andar - sala 411 CEP 05508-050 - Cidade Universitária - Butantã - São Paulo/SP Telefax: (11) 3091-4403

http://www.usp.br/revistausp

e-mail: revisusp@edu.usp.br 


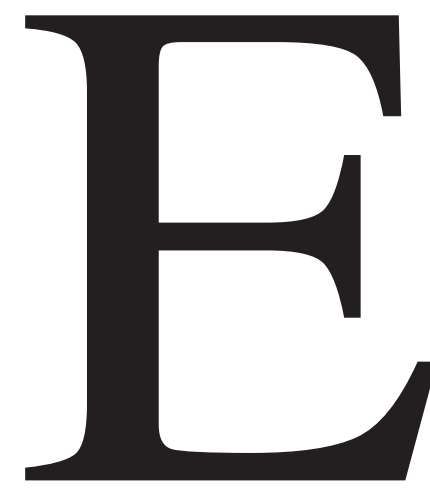

m 1934, graças a uma iniciativa sem precedentes no país, foi criada a Universidade de São Paulo pelo então interventor federal no estado, Armando de Salles Oliveira. Fruto de mentes como Júlio de Mesquita Filho, Fernando de Azevedo, Paulo Duarte e André Dreyfus, ela não foi apenas uma aglutinação de faculdades já existentes, mas se ergueu em torno de uma célula mater, a Faculdade de Filosofia, Ciências e Letras, que renovaria por completo todo o ensino superior brasileiro.

É por demais conhecida a constelação de grandes professores europeus contratada pela USP nos seus primórdios para implantar um padrão acadêmico de alta qualidade, vital para que a universidade começasse a fazer pesquisa de nível internacional. Podemos citar, entre tantos outros, nomes como Roger Bastide, Claude Lévi-Strauss, Giuseppe Ungaretti, Gleb Wataghin e Fidelino de Figueiredo.

São conhecidas também sua ascensão e a manutenção de sua excelência, ao longo do tempo, no cenário do ensino superior do país. Considerada a melhor universidade da América Latina, com atuação fortemente fincada, como toda grande universidade, no tripé ensino, pesquisa e extensão, a USP chegou ao seu octogésimo aniversário responsável por nada menos que $25 \%$ de toda a pesquisa nacional e às voltas com uma crise orçamentária, nos últimos três anos, que lhe tem trazido uma perene dor de cabeça e mobilizado a atual gestão da universidade para sua superação.

Assim, caro leitor, o presente dossiê da revista tem a intenção de esmiuçar esse dilema pelo qual passa a instituição. Universidade em Movimento traz um conjunto indispensável de artigos assinados por especialistas - os artífices mencionados na capa - cuidadosamente selecionados tanto para expor a extensão da crise (ou questioná-la), como para apontar saídas, soluções. Afinal, qual é a USP imaginada para o seu centenário, em 2034 ? 
